\title{
Cathodic protection in reinforced concrete structures affected by macrocell corrosion: a discussion about the significance of the protection criteria
}

\author{
Stéphane Laurens ${ }^{\mathrm{a}}$, Raoul François ${ }^{\mathrm{a}^{*}}$ \\ ${ }^{a}$ LMDC, Université de Toulouse, INSA, UPS, France
}

Received: 15 September 2017 / Accepted: 27 November 2017 / Published online: 5 December 2017

(C) The Author(s) 2017. This article is published with open access and licensed under a Creative Commons Attribution 4.0 International License.

\begin{abstract}
Cathodic protection is a technique that has been used to control corrosion and increase the service life of reinforced concrete structure. Standards as EN ISO 12696 give protection criteria for both impressed current and sacrificial anodes techniques, based on potential value or decay during a depolarization sequence. The polarization (current ON) and depolarization (current OFF) are experimentally studied on a corroded concrete wall using six references electrodes and compared to a time-dependent modelling using FEM software COMSOL Multiphysics. Both experimental and numerical results show significant differences in the time response according to electrode location. This conclusion indicates that the concept of protection criteria defined by the EN ISO 12696 standard is not suitable to assess the efficiency of cathodic protection applied to reinforced concrete structure.
\end{abstract}

Keywords: Impressed Current Cathodic Protection; Corrosion of steel in concrete; Potential mapping; Electrochemical modelling; Performance criterion

\section{Introduction}

Cathodic protection (CP) is a technique used to control (prevent or avoid) the corrosion of a metal by making it work as a cathode in an electrochemical cell. Application of CP on Reinforced Concrete (RC) structure is more recent than its used for marine steel structures (first application in 1824 [1]) or buried steel structures in soil. Nevertheless, CP applied to RC structures is well described since decades both for existing RC structures (cathodic protection) or to new RC structures (cathodic prevention) [2-6]. Here, the electrochemical system is composed of steel reinforcements acting as cathode, concrete as electrolyte and an external anode located on the concrete surface or embedded in the structure. Sacrificial anodes (aluminum, zinc) are used for galvanic cathodic protection, while anodes like mixed metal oxide (MMO) activated titanium mesh or electro-conductive coating connected to a rectifier are used for Impressed Current Cathodic Protection (ICCP). There is no theoretical background for the assessment of efficiency of CP in RC structures. Nevertheless, according to the standard EN ISO 12696 (2016) [7], current densities to be applied for cathodic prevention range between $0.2 \mathrm{~mA} / \mathrm{m}^{2}$ and $2 \mathrm{~mA} / \mathrm{m}^{2}$ of steel reinforcement surface compared with a range of $2 \mathrm{~mA} / \mathrm{m}^{2}$ to $20 \mathrm{~mA} / \mathrm{m}^{2}$ of steel reinforcement for cathodic protection on existing structures [7]. The standard states that protection is ensured when one of the following three conditions is verified for the whole reinforcement:

For any structure, any representative steel in concrete location shall meet any one of the criteria given a) b) c)

a) An "Instant OFF" potential ( $E_{\mathrm{OFF}}$ ) more negative than $-720 \mathrm{mV}$ with respect to $\mathrm{Ag} / \mathrm{AgCl} / 0.5 \mathrm{M} \mathrm{KCl}$ reference electrode; which corresponds to $-680 \mathrm{mV} / \mathrm{SCE}$ (Saturated Calomel Electrode);

b) A potential decay over a maximum period of $24 \mathrm{~h}$ of at least $100 \mathrm{mV}$ from $\mathrm{E}_{\mathrm{OFF}}$;

c) A potential decay over an extended period (typically $24 \mathrm{~h}$ or longer) of at least $150 \mathrm{mV}$ from $\mathrm{E}_{\mathrm{OFF}}$ subject to a continuing decay and the use of reference electrodes (not potential decay probes) for the measurement extended beyond $24 \mathrm{~h}$.

But, the EN ISO 12696 standard also specifies other boundaries: no instant off steel/concrete potential more negative than $-1100 \mathrm{mV}$ with respect to $\mathrm{Ag} / \mathrm{AgCl} / 0.5 \mathrm{M} \mathrm{KCl}$ shall be permitted for plain reinforcing steel or $-900 \mathrm{mV}$ for prestressing steel.

The standards do not provide any specific recommendation on the location of electrodes used to assess the ICCP performance. As a result, the formulations of the performance criteria implicitly indicate that the ICCP leads to an equipotential state of steel reinforced. Indeed, if a 
gradient of potential exists, for example $400 \mathrm{mV}$ between different steel bars, reaching $-720 \mathrm{mV} / \mathrm{AgAgCl}$ in all locations, will lead to reach $-1120 \mathrm{mV} / \mathrm{AgAgCl}$ in some points which will not respect the serviceability criteria (no potential more negative than $-900 \mathrm{mV} / \mathrm{AgAgCl}$ or $-1100 \mathrm{mV} / \mathrm{AgAgCl}$ according to the type of steel reinforcement). Then, the common knowledge of cathodic protection in RC structures, is that corrosion is mitigated due to a decrease in potential gradient along the reinforcement [8]. Despite numerous papers dedicated to the study of the protection current distribution [9-12], only difference in polarization are noted between multi-layers of steel reinforcement layout, or between the surface of steel facing anode and the opposite surface. On the contrary, it should be noted that the CP community working on buried steel already knows for decades the heterogeneity of potential in case of macro-cell system [13]. However, for RC structures, recent works showed that the half-cell potential field in steady-state condition of a macrocell corrosion system under ICCP is not uniform [14]. In order to complete these results, this paper proposes a discussion based on an ICCP system applied to a reinforced concrete wall which is monitored in six different locations simultaneously using six references electrodes. Transient polarization and depolarization processes are monitored for each location. Moreover, a time-dependent numerical simulation is also performed and compared to the experimental measurement.

\section{Experimental program}

A reinforced concrete wall $(75 \mathrm{~cm}$-width $\times 100 \mathrm{~cm}$-height $\times$ $20 \mathrm{~cm}$-thickness) was cast by using Ordinary Portland Cement (OPC); concrete mix: $52.5 \mathrm{~kg}$ of CEM I, $165 \mathrm{~kg}$ gravel, $105 \mathrm{~kg}$ sand and $30 \mathrm{~L}$ of water. Concrete demolding took place 5 days after pouring and the reinforcement consists of 5 horizontal ( $\mathrm{H} 1$ to $\mathrm{H} 5$ ) and 4 vertical (V1 to V4) steel bars with $8 \mathrm{~mm}$-diameter, with concrete covers of 3 and $4 \mathrm{~cm}$ respectively. Reinforced concrete bars could be or not electrically connected to allow the measurement of galvanic current between each bars, as an indicator of macro-cell corrosion. A corrosion spot was initiated by chloride migration from a peculiar point of the concrete surface. The migration system consisted of 2 plastic elbows sticked on both sides of the concrete wall. The first one was filled with a solution of $0.5 \mathrm{M} \mathrm{NaCl}$ and the second with $0.5 \mathrm{M} \mathrm{NaOH}$. A voltage of $5 \mathrm{~V}$ was maintained between the two solution containers, using $\mathrm{MMO}$ titanium electrodes, until chlorideinduced corrosion initiated on embedded steel bars close to the chloride source. Corrosion occurrence was checked by the appearance of galvanic current between bar V3 and the others bars of the reinforcement layer. Therefore, only the concrete volume surrounding the corrosion spot was contaminated by chlorides. No significant polarization of the reinforcement layout was assumed because steel bars were not used as electrodes in the migration process. The experimental program shown in this paper was performed more than one year after the migration of chlorides: we assumed that pore solution reverted back to the usual condition of concrete with chloride penetration through diffusion process.

The wall was stored in a room kept at a constant temperature $22^{\circ} \mathrm{C}$ and some carbonation and then some carbonation-induced corrosion occured at the interface with vertical bars V3 and V4 which go out of the wall for the purpose of proceed to external electrical connection between rebars (Fig. 1), because of a lack of coating at the intersection between concrete surface and the rebars.

The ICCP technique was implemented using a MMO activated titanium mesh embedded in mortar on the rear side of the wall, as anodic system. The titanium mesh was then located at the distance of $16 \mathrm{~cm}$ of the reinforcement layout.

To avoid that the concrete was too dry for corrosion development, wetting-dry cycles with water aspersion were performed periodically, for one hour each 15 days.

The potential was monitored by using an internal $M_{n} / M_{n} O_{2}$ electrode embedded in the wall (noted internal) and five saturated calomel electrodes (SCE) located at differents points of the wall surface (s1 to s5) (see on Fig. 2). In accordance with EN ISO standard 12696, a protection current corresponding to $15 \mathrm{~mA} / \mathrm{m}^{2}$ of steel was applied.

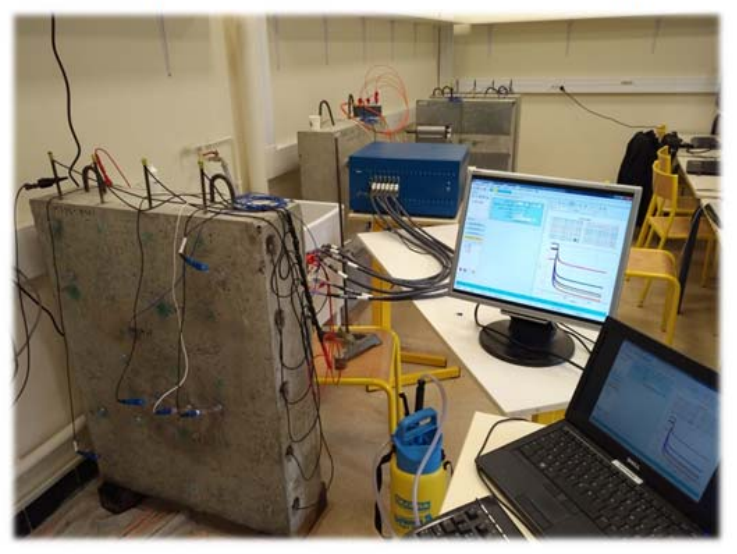

Figure 1. Reinforced concrete wall monitored by a six-channels potentiostat-galvanostat.

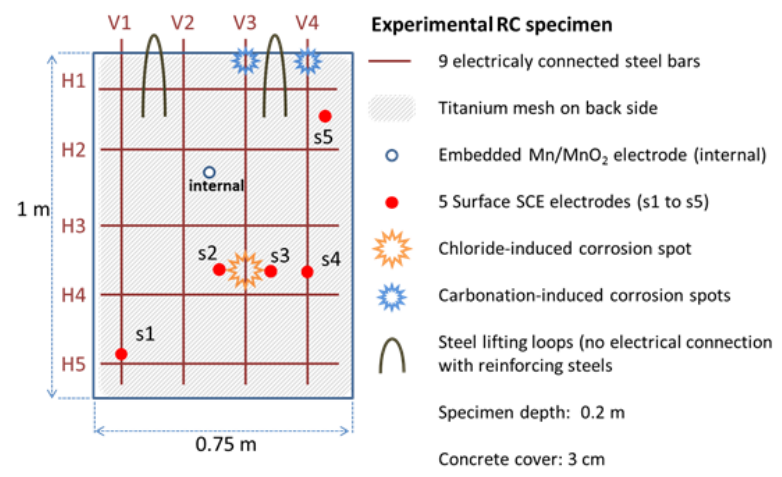

Figure 2. Scheme of the experimental reinforced concrete wall and location of the different references electrodes.

The ICCP experiment is conducted by using a Bio-Logic ${ }^{\bullet} 6$ channels potentiostat-galvanostat (Fig. 1). One channel is 
used to impress the polarizing current and monitor the potential of one of the six electrodes. The 5 remaining channels are used only to collect potentials relative to the other electrodes.

\section{Experimental results}

The polarization and depolarization of the reinforcement layout monitored by the six references electrodes are shown in Fig. 3. All the potential are expressed versus the SCE reference. Fig. 3 shows the transient response when electrical current is applied including the ohmic drops (which depend of the location of the reference electrode) and then the progressive stabilization of potentials corresponding to the steady-state response. Acquisition frequency is $0.1 \mathrm{~s}$ during the first 10 minutes of polarization and depolarization processes, then the frequency is switched to $1 \mathrm{~s}$.

As an example, Fig. 3 shows also for one electrode (s1) the different steps and value of the potential versus time:

- $E_{0}$ free potential at the electrode location (structure without cathodic protection)

- $E_{\mathrm{ON}}$ potential when the impressed current is applied, firstly an instantaneous decrease in the potential corresponding to the ohmic drop, then the ongoing polarization.

- $E_{\text {OFF }}$ potential when the impressed current is cut off, firstly an instantaneous increase in potential corresponding to the ohmic drop to reach the so-called instant-OFF potential $\left(\mathrm{E}_{\mathrm{OFF}}\right)$ which is, according to standard EN ISO 12696, assumed to be the true potential at the steel-concrete interface during the polarization (current $\mathrm{ON}$ ) since it corresponds to the potential $E_{\mathrm{ON}}$ corrected of the ohmic drop. This is the reason why the first performance criterion of cathodic protection is based on this $\mathrm{E}_{\mathrm{OFF}}$ potential.

- The depolarization takes place after the ohmic drop, which lead to a decay corresponding to the difference between $\mathrm{E}_{\mathrm{OFF}}$ and the potential recorded during time. The second and third criteria of cathodic protection performance are based on this decay.

In order to get a comprehensive description of the local responses in terms of polarization and depolarization, the ohmic drop, arbitrarily evaluated after $0.5 \mathrm{~s}$, is then systematically subtracted to the collected potential for each electrode. This processing allows for clearly comparing the polarization and depolarization time series relative to each spatial location. The results are plotted in Fig. 4.

From Fig. 4, it is clear that both polarization and depolarization processes are not uniform in the concrete wall. Even for a small size reinforced concrete wall, the polarization or depolarization could vary by a factor of two according to the measurement location.

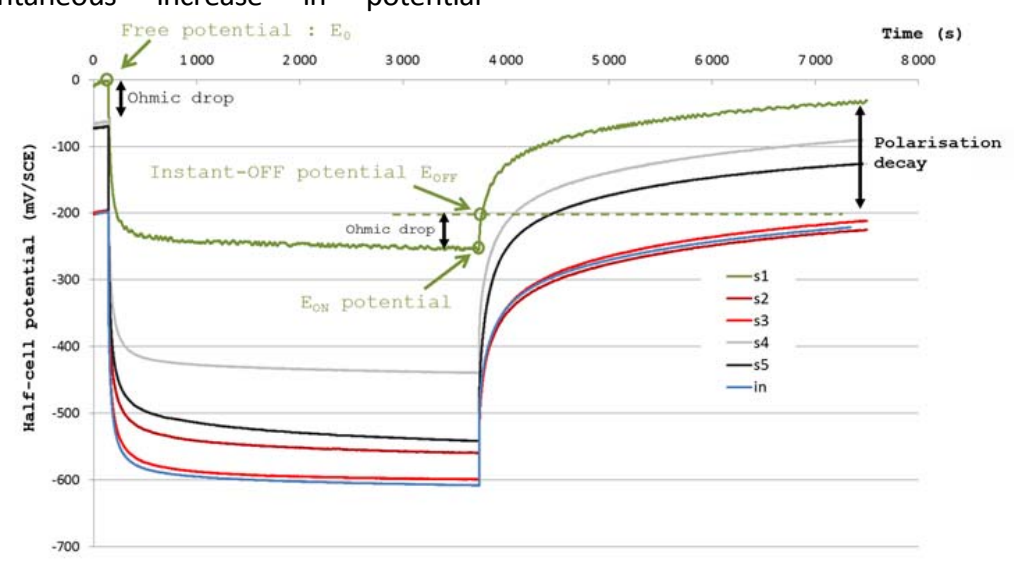

Figure 3. ICCP experiment - polarization and depolarization processes (all potentials are expressed versus SCE reference).
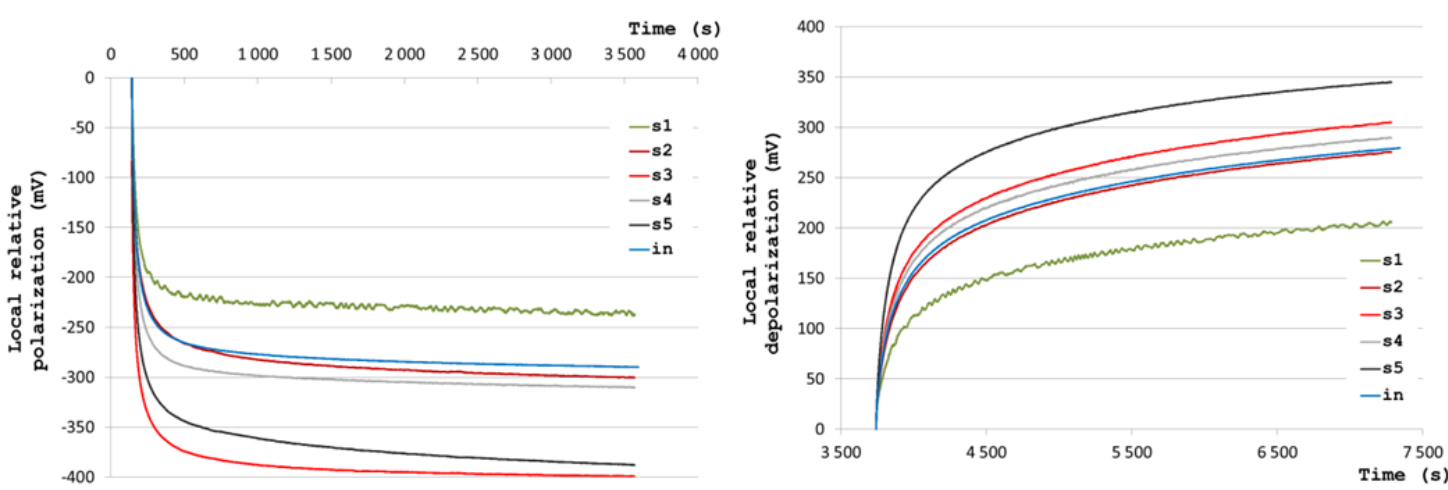

Figure 4. Local relative polarization (left) and depolarization (right) time series. 
Moreover the instant-OFF potential, $\mathrm{E}_{\mathrm{OFF}}$, which is shown in Table 1 is also very sensitive to the location of reference electrodes with a minimal value of $-519 \mathrm{mV} / \mathrm{SCE}$ and a maximal value of $-240 \mathrm{mV} / \mathrm{SCE}$. These experimental results show that the localized corrosion occurring in reinforced concrete lead to a non-uniform polarization under cathodic protection. As a result, it indicates that the first criterion of cathodic protection performance, based on the concept of equipotential steel, is not appropriate. Indeed, $E_{\text {OFF }}$ is supposed to give the true potential at steel interface during the application of the ICCP and this potential is implicitly assumed to be identical in all points of the reinforced concrete structure.

Table 1. Current-On and Instant-Off potentials, ohmic drop and $1 \mathrm{~h}$ decay for the different references electrodes.

\begin{tabular}{|l|l|l|l|l|}
\hline $\begin{array}{l}\text { Reference } \\
\text { electrode }\end{array}$ & $\begin{array}{l}\mathrm{E}_{\mathrm{ON}} \\
(\mathrm{mV} / \mathrm{SCE})\end{array}$ & $\begin{array}{l}\mathrm{E}_{\mathrm{OFF}} \\
(\mathrm{mV} / \mathrm{SCE})\end{array}$ & $\begin{array}{l}\text { IR drop } \\
(\mathrm{mV})\end{array}$ & $\begin{array}{l}1 \mathrm{~h} \text { decay } \\
(\mathrm{mV})\end{array}$ \\
\hline $\mathrm{s} 1$ & -253 & -240 & 13 & 209 \\
\hline s2 & -560 & -503 & 57 & 278 \\
\hline s3 & -599 & -519 & 80 & 308 \\
\hline s4 & -439 & -382 & 57 & 292 \\
\hline s5 & -542 & -473 & 69 & 347 \\
\hline in & -608 & -501 & 107 & 279 \\
\hline
\end{tabular}

As shown in Fig. 4 (right), the depolarization responses are also not uniform in the reinforced concrete wall. Table 1 shows that the depolarization decays after one hour vary from $209 \mathrm{mV}$ to $347 \mathrm{mV}$ depending to the location of the reference electrode. As a result, the second criterion is clearly fulfilled since the one $h$ and furthermore the 24h-depolarization are greater than $100 \mathrm{mV}$. Nevertheless, at least two questions emerge:

- the differences between values recorded at different locations (maximal difference $=66 \%$ ) show that the location of the reference electrode (or decay probe) is actually a relevant issue,

- the large difference between the value prescribed by standard EN ISO $12696(100 \mathrm{mV})$ and the values recorded (up to $347 \mathrm{mV}$ ) raise some relevant questions: is it the consequence of lack of understanding of polarization by the second criterion or on the contrary is it the result of excessive polarization?

\section{$4 \quad$ Numerical simulation}

In order to corroborate this experimental result, complementary numerical experiments were conducted by using the FEM software Comsol Multiphysics ${ }^{\circledR}$. The modelling approach attempts to characterize the transient response of the concrete wall under cathodic protection and, after cut-off, during depolarization. The transient response of reinforcing steel boundaries was simply modelled here by a surface impedance (Eq.1), involving a surface resistance corresponding to a polarization resistance $R_{p}\left(\Omega \cdot m^{2}\right)$ and a surface capacitance $C\left(F / m^{2}\right)$.

$$
j_{n}=\left(\frac{1}{R_{p}}+C \frac{\partial}{\partial t}\right)\left(E-E_{\text {corr }}\right)
$$

Where $j_{n}$ is the current density flowing normally through the steel boundary and $E-E_{c o r r}$, the polarization undergone locally by the steel. Appropriate values of $R_{p}$ and $E_{\text {corr }}$ were set to distinguish active and passive steel areas, while the same capacitance was defined for the whole steel surface. A ratio of 100 corresponding to the difference in steady state response under anodic polarization between passive state and active state of steel in presence of chlorides was used according to authors own experience. The polarizing current was applied by setting a floating potential condition on the back side of the wall, where the titanium activated mesh is located. In the concrete volume, local Ohm's law (Eq.2) and charge conservation (Eq.3) were implemented.

$$
\begin{aligned}
& \boldsymbol{j}=-\frac{1}{\rho} \nabla E \\
& \nabla . \boldsymbol{j}=0
\end{aligned}
$$

This modelling approach is clearly simplified since the exponential behaviour related to the Butler-Volmer polarization model is not taken into account by the surface impedance assumption (Fig. 5), leading to quantitative errors. Nevertheless, it provides a relevant qualitative response of the transient behaviour of the steel during the test (polarization and depolarization).

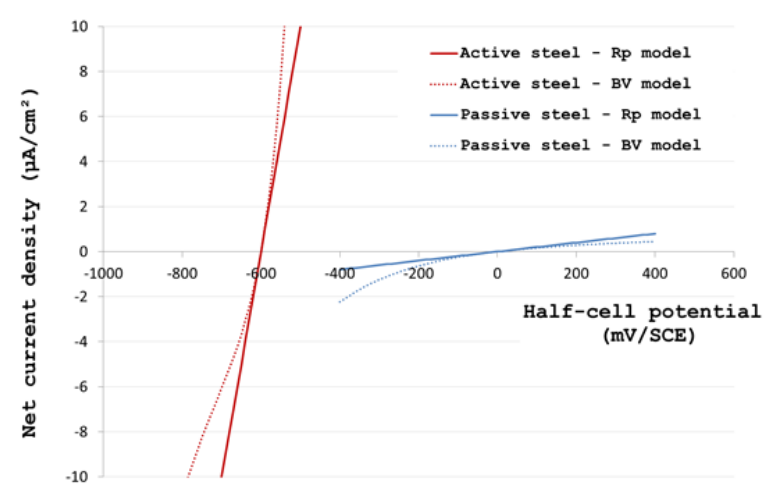

Figure 5. simplified linear approach for the resistance of polarization of both active and passive steel area instead of BV (Butler-Volmer) responses.

The Fig. 6 presents the result of the numerical simulation of the whole ICCP experiment: current-on and current-off. The time series obtained for the different electrode locations show a good qualitative agreement with experimental results. In particular, the hierarchy of the experimental 6 curves is almost exactly respected by the simulation.

At last, the Fig. 7 plots the simulated local relative polarization and depolarization for the 6 reference electrodes. The qualitative accordance with experimental results presented in the Fig. 4 is observed. It has to be noted here that each polarization and related depolarization time series are exactly symmetrical, since mass production and transport effects were not taken into account in the 
modelling approach. Consequently, the simulated system revert back exactly to its initial state.

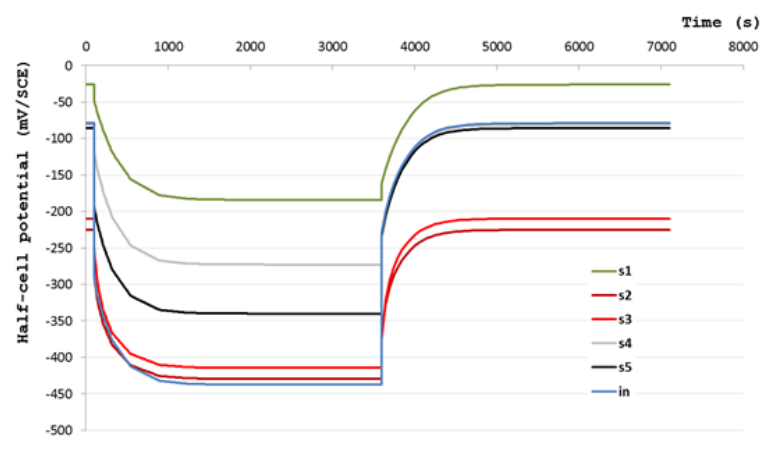

Figure 6. Numerical simulation of the ICCP experiment.

This simulation work confirms from a theoretical point of view that, in the case of macrocell corrosion systems, there is no physical justification of the assumed uniformity of the electrochemical state of the reinforcing steel layout under cathodic protection. Improving the quality of the modelling approach (Butler-Volmer instead of simple polarization resistance, consideration of mass transport effects...) would lead to a better quantitative agreement between experiments and simulation, but would not change in any way the qualitative statement just mentioned above. Macrocell corrosion systems in reinforced concrete exhibit non-uniform potential fields before external polarization, during cathodic protection and after current cut-off (during depolarization).

\section{Discussion - Conclusion}

This paper discusses the results of an ICCP experiment performed on reinforced concrete wall affected by macrocell corrosion. During the test, transient potentials (polarization and depolarization) were monitored simultaneously in six spatial locations by using six reference electrodes. The paper also shows a preliminary modelling approach of the timedependent behaviour of steel under cathodic protection and after cut-off, based on a simple assumption of surface impedance involving polarization resistance and surface capacitance.
Both experimental and numerical results confirm the nonuniform polarization and non-uniform depolarization during cathodic protection applied to reinforced concrete. Moreover, the comparison between experimental measurements and numerical simulation is very encouraging and shows a quite good agreement in a qualitative point of view.

As stated by Saguës and Kranc [15], a careful attention should be paid to instant-off potentials measured on macrocell corrosion system, which are actually difficult to interpret. The results presented in this paper highlight this conclusion. The significant differences between the instantoff potential values collected at the 6 locations clearly show that the $E_{\text {OfF }}$ potential (so called "true potential") at steel interface is never uniform in the case of macrocell corrosion, even under cathodic protection, and call into question the actual relevance of this information.

A first consequence of these observations is that the verification of the first cathodic protection criterion defined by the standard EN ISO 12696 is not suitable, since it is implicitly based on the assumption of equipotential steel under cathodic protection. A second aspect of the first criteria is to reach a potential below $(-720 \mathrm{mV} / \mathrm{Ag} / \mathrm{AgCl} 0.5 \mathrm{M}$ or $-680 \mathrm{mV} / \mathrm{SCE})$. It corresponds to "restoring the passivity" of steel in chloride contaminated concrete. Bertolini et al. [16] already stated that it is not necessary to reach such a potential to reduce the macrocouple activity on its surface. But the results presented in this paper make a supplementary step indicating that a criterion expressed in terms of potential value is a not suitable for reinforced concrete structures under ICCP, because of the nonuniformity of potential field.

A second consequence of these observations is that the verification of the second and third cathodic protection criteria depends mainly on the location of embedded decay probes and reference electrodes. As a result, the question of the proper measuring position to validate the operation of a cathodic protection installation is fully opened: in other words, are the criteria verified everywhere if verified somewhere? And are the criteria verified somewhere guaranteed that no over-polarization, or under-polarization is applied elsewhere?
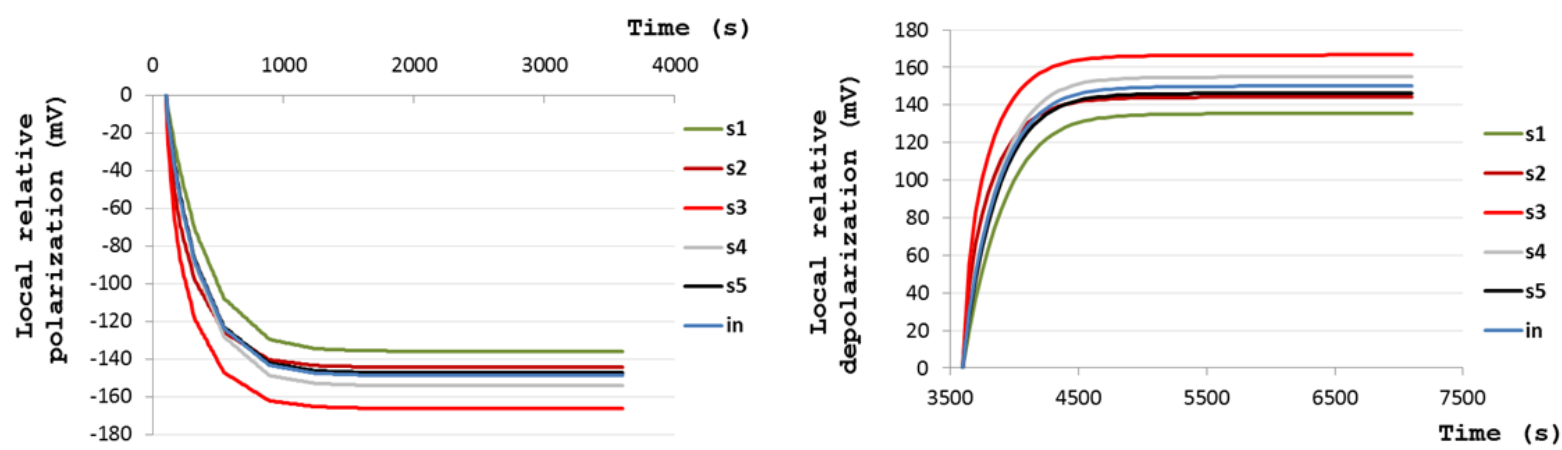

Figure 7. Local relative polarization (left) and depolarization (right) time series 
A third consequence of these observations is that the verification of the absence of hydrogen embrittlement which is achieved if the potential is not brought to the $-900 \mathrm{mV}$ $\mathrm{Ag} / \mathrm{AgCl}$ according to the standard EN ISO 12696 (value at which hydrogen evolution can take place). This paper shows it is not suitable since it is also implicitly based on the assumption of equipotential steel under cathodic protection.

Finally, it should be highlighted that the discussion about the significance of IR drop is already a subject of debate for many years in the CP community dedicated to buried steel [17]. It is then necessary that the CP community working on $\mathrm{RC}$ structures also accepted to review the generally understanding concept of CP to point out the limitations of existing protection criteria and suggested new criteria. According to the paper results, a universal criterion seems difficult and may be impossible to propose. Authors think that performance criteria must be adapted to the geometry, environment and macro-cell corrosion system of each RC structure, through a 3D numerical simulation of its behaviour.

\section{References}

[1] H. Davy, On the corrosion of copper sheeting by seawater, and on methods of preventing this effect, and on their application to ships of war and other ships. Proceedings of the Royal Society (1824) 114: 151-158.

[2] R. B. Polder, Cathodic Protection of Reinforced Concrete Structures in The Netherlands - experience and developments. HERON (1998) 43: 3-14.

[3] P. Pedeferri, Cathodic protection and cathodic prevention. Constr Build Mater (1995) 10: 391-402. https://doi.org/10.1016/0950-0618(95)00017-8

[4] L. Bertolini, A tribute to Pietro Pedeferri's contribution to the knowledge on corrosion ofsteel in concrete and its prevention. Mater Corros (2011) 62: 96-97. https://doi.org/10.1002/maco.201190006

[5] L. Bertolini, F. Bolzoni, A. Cigada, T. Pastore, P. Pedeferri, Cathodic protection of new and old reinforced concrete structures. Corros Sci (1993) 35: 1633-1639. https://doi.org/10.1016/0010-938X(93)90393-U

[6] L. Bertolini, B. Elsener, P. Pedeferri, E. Redaelli, R. Polder, Corrosion of steel in concrete: Prevention, diagnosis, repair (2nd ed.) (2013). Weinheim, Germany: Wiley VCH. https://doi.org/10.1002/9783527651696

[7] EN ISO 12696 standard, Cathodic protection of steel in concrete ISO 12696, 2016.

[8] NACE International, CP-2 Cathodic Protection Technician Course Manual, Nace, Houston 2000.

[9] M.M.S. Cheung, C. Cao, Application of cathodic protection for controlling macrocell corrosion in chloride contaminated RC structures. Constr Build Mater (2013) 45: 199-207. https://doi.org/10.1016/j.conbuildmat.2013.04.010

[10] A. M. Hassanein, G. K. Glass, N. R. Buenfeld, Protection current distribution in reinforced concrete cathodic protection systems. Cem Concr Compos (2002) 24: 159-167. https://doi.org/10.1016/S0958-9465(01)00036-1

[11] G. Qiao, B. Guo, J. Ou, F. Xu, Z. Li, Numerical optimization of an impressed current cathodic protection system for reinforced concrete structures. Constr Build Mater (2016) 119: 260-267. https://doi.org/10.1016/i.conbuildmat.2016.05.012

[12] M. Bruns, M. Raupach, Protection of the opposite reinforcement layer of RC-structures by $\mathrm{CP}$ - results of numerical simulations. Mater Corros (2010) 61: 505-511. https://doi.org/10.1002/maco.200905584

[13] U. Angst, M. Büchler, B. Martin, H. G. Schöneich, G. Haynes, S. Leeds, F. Kajiyama, Cathodic protection of soil buried steel pipelines - a critical discussion of protection criteria and threshold values.
Mater Corros (2016) 67: 1135-1142.

https://doi.org/10.1002/maco.201608862

[14] E. Sassine, S. Laurens, R. François, E. Ringot, Experiments and numerical simulations on Impressed Current Cathodic Protection technique applied to steel reinforced concrete structures. Proceedings of the EUROCORR 2016 Montpellier, France, September 2016.

[15] A. A. Sagües, S. C Kranc, On the determination of polarization diagrams of reinforcing steel in concrete. Corrosion (1992) 48: 624633. https://doi.org/10.5006/1.3315982

[16] L. Bertolini, F. Bolzoni, P. Pedeferri, L. Lazzari, T. Pastore, Cathodic protection and cathodic prevention in concrete: principles and applications. J Appl Electrochem (1998) 28: 1321-1331. https://doi.org/10.1023/A:1003404428827

[17] U. Angst, M. Büchler, Impact of IR drop on the $-850 \mathrm{mV}_{\text {CSE }}$ Cathodic protection criterion for coated steel pipes in soil. J Pipeline Syst Eng Pract (in press). https://doi.org/10.1061/(ASCE) PS.1949-1204.0000306 